\title{
Article
}

\section{Skin-Deep Surface Patterning of Calcite}

Green, David C., Shida, Yosuke, Honma, Nobuyuki, Holden, Mark, Kim, Yi-Yeoun, Kulak, Alexander N., Ogasawara, Wataru and Meldrum, Fiona C.

Available at https://clok.uclan.ac.uk/30834/

Green, David C., Shida, Yosuke, Honma, Nobuyuki, Holden, Mark orcid iconORCID: 0000-0003-3060-7615, Kim, Yi-Yeoun, Kulak, Alexander N., Ogasawara, Wataru and Meldrum, Fiona C. (2019) Skin-Deep Surface Patterning of Calcite. Chemistry of Materials, 31 (21). pp. 8725-8733. ISSN $0897-4756$

It is advisable to refer to the publisher's version if you intend to cite from the work. http://dx.doi.org/10.1021/acs.chemmater.9b02421

For more information about UCLan's research in this area go to http://www.uclan.ac.uk/researchgroups/ and search for <name of research Group>.

For information about Research generally at UCLan please go to http://www.uclan.ac.uk/research/

All outputs in CLoK are protected by Intellectual Property Rights law, including Copyright law. Copyright, IPR and Moral Rights for the works on this site are retained by the individual authors and/or other copyright owners. Terms and conditions for use of this material are defined in the policies page.

\section{CLoK}

Central Lancashire online Knowledge www.clok.uclan.ac.uk

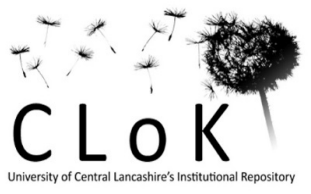




\section{UNIVERSITY OF LEEDS}

This is a repository copy of Skin-Deep Surface Patterning of Calcite.

White Rose Research Online URL for this paper:

http://eprints.whiterose.ac.uk/152322/

Version: Accepted Version

\section{Article:}

Green, DC, Shida, Y, Honma, N et al. (5 more authors) (2019) Skin-Deep Surface

Patterning of Calcite. Chemistry of Materials. ISSN 0897-4756

https://doi.org/10.1021/acs.chemmater.9b02421

(C) 2019 American Chemical Society. This is an author produced version of a paper published in Chemistry of Materials. Uploaded in accordance with the publisher's self-archiving policy.

\section{Reuse}

Items deposited in White Rose Research Online are protected by copyright, with all rights reserved unless indicated otherwise. They may be downloaded and/or printed for private study, or other acts as permitted by national copyright laws. The publisher or other rights holders may allow further reproduction and re-use of the full text version. This is indicated by the licence information on the White Rose Research Online record for the item.

\section{Takedown}

If you consider content in White Rose Research Online to be in breach of UK law, please notify us by emailing eprints@whiterose.ac.uk including the URL of the record and the reason for the withdrawal request. 


\title{
Skin-deep Surface Patterning of Calcite
}

\author{
David C. Green ${ }^{\dagger}, *$, Yosuke Shida ${ }^{\ddagger}$, Nobuyuki Honma ${ }^{\ddagger}$, Mark A. Holden ${ }^{\dagger}$, , Yi-Yeoun Kim ${ }^{\dagger}$, \\ Alexander N. Kulak ${ }^{\dagger}$, Wataru Ogasawara ${ }^{\star}$ and Fiona C. Meldrum ${ }^{\dagger}$
}

\author{
${ }^{\dagger}$ School of Chemistry, University of Leeds, Leeds, LS2 9JT, UK, \\ Department of Bioengineering, Nagaoka University of Technology, 1603-1 Kamitomioka, Nagaoka, \\ Niigata 940-2188, Japan
}

The influence of soluble additives on the growth of calcite $\left(\mathrm{CaCO}_{3}\right)$ is usually rationalized based on changes in crystal morphologies, where preferential association of the additives with either the acute or obtuse steps on the crystal surface gives rise to specific growth forms. In this work we investigate the influence of a highly acidic organic additive with calcite - cp20k from the barnacle Megabalanus rosa - and demonstrate that in addition to modifying the crystal morphology, additives can be used to generate calcite crystals with different surface architectures. These can potentially rise to interesting optical effects that may be important in applications such as in coatings and paints. These surface features form during dissolution/reprecipitation at the crystal surface during the incubation of crystals in solution, and confocal fluorescence microscopy confirmed they are limited to the surface of the crystal only. The surface patterning can also be tuned using alternative additives, mixtures of additives and by varying the solution conditions. Notably, we also show that surface structures can be used to determine the mode of interaction of additives with the microscopic surface steps under conditions where only minor changes in morphology have occurred.

\section{Introduction.}

Soluble additives provide one of the most effective means of controlling crystallization processes, where they can enable selection of morphology, size and even polymorph. ${ }^{1}$ Significant efforts have therefore been made to understand the origins of their activities, with the overall goal of being able to design additives that can deliver specific products. One of the best studied systems is calcium carbonate, where it exhibits multiple polymorphs under ambient conditions, and the morphology of crystals can be altered using a range of strategies. Atomic force microscopy (AFM $)^{2}$ and modelling studies ${ }^{3}$ have revealed how additives interact with growing calcite crystals on a microscopic scale, and how this translates into macroscopic changes in single crystal morphologies. The resultant crystals can therefore be classified into a number of basic morphological forms depending on whether the additives preferentially bind to the acute or obtuse steps on the calcite $\{104\}$ faces.

A further property of crystalline particles that has received far less attention, but that can also play an important role in many applications, is their surface topography. The presence of regular surface features can give rise to interesting optical effects including structural colour ${ }^{4}$ or light-trapping, ${ }^{5}$ where light scattering by the crystal surfaces is particularly important in applications such as in coatings and paints. While nanostructuring of surfaces is often achieved using top-down lithographic methods, there is enormous potential to use additives - either during crystal growth or dissolution - to create unique surface patterns. Many interesting surface structures have been generated using soluble additives, ${ }^{6}$ or by growing crystals in gels. ${ }^{7} 8$ Notably, calcite surfaces patterned with nanoshoots have been generated in the presence of additives using dissolution protocols. ${ }^{9,} 10$ Again, the surfaces structures formed are expected to reflect the modes of interaction of the additives with the crystal, such that it should be possible to program different surface topographies based on an understanding of the crystal/additive interactions.

Here, we employ a model organic additive - cp20k - and explore how it can be used in combination with different crystal growth conditions to generate calcite crystals with different surface patterns. 
cp20k is found in the water-soluble fraction of the cement proteins of the barnacle Megabalanus rosa, and was selected due its high acid content and therefore strong binding to calcite. ${ }^{11-13}$ We demonstrate that distinct surface architectures ranging from striations to nanoshoot bunches can be achieved according to the experimental conditions employed, and that the range of accessible structures can be further increased by addition of magnesium ions. Structural characterization of the crystals shows that these surface structures are limited to a zone close to the surface of the crystal, and are accompanied by protein incorporation. The surface structures formed can be rationalized in terms of the microscopic crystal/ additive interactions, where this provides a framework for creating specific surface structures as desired.

\section{Results and Discussion}

Calcite Precipitation with Barnacle Cement Protein (cp20k): cp20k was expressed from $E$ coli and purified into DI water; $\approx 1 \%$ of the protein was fluorescently tagged to enable analysis by confocal fluorescence microscopy (CFM). cp20k contains $\approx 22 \%$ acidic amino acids (Table S1), $\approx 16 \%$ cysteine, and is negatively charged above $\mathrm{pH} 5.5$ (Figure $\mathrm{S} 1$ ). It was then used in crystal growth experiments, where calcite was precipitated using the carbonate direct mixing (CDM) method in which $\mathrm{Na}_{2} \mathrm{CO}_{3}$ solution was added to a $\mathrm{CaCl}_{2} /$ additive solution to yield concentrations of $\left[\mathrm{Ca}^{2+}\right]=\left[\mathrm{CO}_{3}{ }^{2-}\right]=5 \mathrm{mM}$. Crystals were allowed to grow over 5 days and were identified as calcite by Raman spectroscopy (Figure S2). Control experiments performed in the absence of protein yielded rhombohedral calcite crystals.

cp20k induced changes in both the morphology and surface topography of the calcite crystals. Considering first morphology, increasing the concentration of cp20k from 0.005 to $0.015 \mathrm{mg} / \mathrm{mL}$ resulted in an elongation of the crystals along the $c$-axis, and the ultimate formation of a dumbbell shape (Figure 1 and Figure S3). These crystals were confirmed as single crystals using polarized light microscopy (PLM) (Figure S4). All of the crystals exhibited 3-fold symmetry when viewed perpendicular to the $c$-axis, and a transition from being capped by three smooth $\{104\}$ faces to a highly rough surface occurred as the protein concentration increased. These morphological changes were also accompanied by an increase in the surface roughness (Figure 1). Between [cp20k] $=0.025$ and 0.05 $\mathrm{mg} / \mathrm{mL}$, the surfaces of the crystals were dominated by bundled nanoshoots (Figure 1), while at [cp20k] $=0.075$ and $0.095 \mathrm{mg} / \mathrm{mL}$, dumbbell-shaped structures composed of bundled nanoshoots were observed. Nanoshoot bundles were visible length-wise upon the new pseudofaces oriented parallel to the $c$-axis (Figure 1). Investigation of a cross-section through individual crystals demonstrated that the surface patterns are only associated with the outer surface of the crystal. For crystals exhibiting nanoshoots (produced at $[\mathrm{cp} 20 \mathrm{k}]=0.015 \mathrm{mg} / \mathrm{mL}$ ) this reached a depth of $\approx 450-700 \mathrm{~nm}$ below the crystal surface (Figure 2a), and confocal laser fluorescence microscopy (CLFM) showed that the protein was only detectable in this zone (Figure $2 b$ ). This shows that the surface patterns form during the slow growth that occurs during the final stage of crystallization, or in the dissolution/precipitation - or restructuring - regime that occurs after crystallization has terminated and the solution is at equilibrium with respect to calcite. ${ }^{3}$

Influence of Crystal Growth Conditions and cp20k: That the surface patterning is also dependent on the crystallization conditions was demonstrated by precipitating crystals from a solution containing $[\mathrm{cp} 20 \mathrm{k}]=0.015 \mathrm{mg} / \mathrm{mL}$ and $\left[\mathrm{CaCl}_{2}\right]=5 \mathrm{mM}$ using the ammonium diffusion method (ADM). ${ }^{14}$ This presents a contrasting reaction profile to CDM. The slow dissolution of ammonia and carbon dioxide caused the supersaturation and $\mathrm{pH}$ to increase slowly in ADM, whereas this change is much more rapid in CDM conditions. Rhombohedral calcite crystals with roughened pseudo-faces formed after exposure of the $\mathrm{CaCl}_{2} / \mathrm{cp} 20 \mathrm{k}$ solution to a $\mathrm{NH}_{3} / \mathrm{CO}_{2}$ atmosphere for 5 days (Figure S5). Unlike calcite precipitated at the same $\mathrm{CaCl}_{2} / \mathrm{cp} 20 \mathrm{k}$ concentrations using the CDM method, the $\{104\}$ faces showed no oriented surface patterning.

Evolution of Surface Patterning: Our data demonstrate that the patterns seen on the crystal faces are restricted to a surface zone

such that they form (i) during the slow growth period at the end of crystallization, or (ii) after the primary crystal growth period has ended, when the crystal surface undergoes a dynamic dissolution/reprecipitation process. ${ }^{3}$ This mechanism was further investigated by precipitating calcite in the presence of $[\mathrm{cp} 20 \mathrm{k}]=0.015 \mathrm{mg} / \mathrm{mL}$, and terminating the reaction at different times (Figure 3). 
Most growth is conducted within the first $\approx 30 \mathrm{~min}$, but crystals were incubated in the growth solution for up to 5 days. No fluorescence was detected after $10 \mathrm{~min}$, but after $30 \mathrm{~min}$ fluorescence was observed at the acute edges. Signal was detected on $\{104\}$ faces after $1-2 \mathrm{~h}$, and they were entirely covered after 5 days. This progressive increase in protein associated with the $\{104\}$ faces parallels the increase in the surface roughness. Calcite seeds were also placed in an aqueous solution of [cp20k] $=0.015 \mathrm{mg} / \mathrm{mL}$ at $65{ }^{\circ} \mathrm{C}$ for $16 \mathrm{~h}$, thereby mimicking the conditions previously reported to produce nanoshoots. ${ }^{10}$ The vessel was sealed to focus on dissolution (where no further $\mathrm{CO}_{2}$ enters the system) or was left open, where continuous influx of atmospheric $\mathrm{CO}_{2}$ and evaporation-driven increased $\mathrm{Ca}^{2+} /$ additive concentration promotes restructuring. Both conditions led to the formation of striations parallel to the [421] direction on the crystal surfaces, where they were slightly more pronounced in the open system (Figure 4). CLFM showed that only very low levels of cp20k were associated with the surfaces after dissolution (Figures S6), while the protein was located in a $2 \mu \mathrm{m}$ thick surface zone after restructuring

Influence of cp20k and Magnesium Ions: We then investigated the influence of additive mixtures on surface patterning, where these can act co-operatively to generate more complex structures. ${ }^{15}$ Magnesium ions were used in combination with cp20k due to their potent effect on calcite growth, ${ }^{1,16-}$ ${ }^{18}$ and their known influence on surface roughness. ${ }^{6}$ The [cp20k] was fixed at $0.015 \mathrm{mg} / \mathrm{mL}$ and $\mathrm{MgCl}_{2}$ was added to give $\left[\mathrm{Mg}^{2+}\right] /\left[\mathrm{Ca}^{2+}\right]=0.5$ or 1 . Precipitation using the $\mathrm{CDM}$ method yielded calcite crystals with morphologies that were dominated by interaction with the $\mathrm{Mg}^{2+}$ ions (Figure 5a and Figure S7). Higher magnification images of the surfaces of crystals precipitated at $[\mathrm{cp} 20 \mathrm{k}]=0.015 \mathrm{mg} / \mathrm{mL}$ with $\left[\mathrm{Mg}^{2+}\right] /\left[\mathrm{Ca}^{2+}\right]=0.5$ revealed nanoshoots with average diameters of $17 \mathrm{~nm}$ (Figure 5a), where these were elongated along crystallographic $c$ direction, determined by comparing the nanoshoot orientation with respect to [018] reflections in selected area electron diffraction (SAED) data (Figure 6a). The same orientation was observed when $\left[\mathrm{Mg}^{2+}\right] /\left[\mathrm{Ca}^{2+}\right]$ ratio was increased to 1.0 , (Figure $6 \mathrm{~b}$ ) however the nanoshoot diameter decreased to $14 \mathrm{~nm}$.

Precipitation using the ADM provided access to even greater surface patterning. Crystals grown at $\left[\mathrm{Mg}^{2+}\right] /\left[\mathrm{Ca}^{2+}\right]=0.5$ exhibited arrow-shaped features that were co-aligned over the crystal surface. The arrows point in a [001] direction (Figure 5b), and each arrowhead is capped by $\{104\}$ facets. Higher $\left[\mathrm{Mg}^{2+}\right] /\left[\mathrm{Ca}^{2+}\right]=1$ disrupts the arrowhead structure (Figure S7). This demonstrates the potential of controlling surface topography with additive combination. Used separately at the same concentrations, these additives do not induce comparable morphological or ordered surface roughening.

Alternative Additives: The results with cp20k were finally compared with a range of alternative additives, where these were selected due to their reported influence on calcite growth: poly(acrylic acid sodium salt) (PAA), ${ }^{19}$ poly(styrene sulfonate sodium salt) (PSS), ${ }^{20,}{ }^{21}$ poly(styrene sulfonate sodium salt)-alt- poly(maleic acid sodium salt) (PSS-MA), ${ }^{22,}{ }^{23}$ magnesium ions, ${ }^{1,}{ }^{20}$ and formamide. ${ }^{10}$ In common with the $\mathrm{cp} 20 \mathrm{k}$, all of these additives also induce different surface patterning according to whether they were precipitated using the CDM or ADM, and whether they were formed during dissolution or restructuring. For example, PAA yielded indistinct roughness in growth studies (Figure S8), but nanoshoots oriented in calcite's crystallographic $c$ axis during dissolution (Figure 7a), and surface overgrowth codirectional with calcite's [421] during dissolution/restructuring (Figure 7b). The nanoshoots were similar to those observed after dissolution in the presence of formamide (Figure 7c), whereas rough overgrowths were comparable to those formed during growth in the presence of $\mathrm{Mg}^{2+}$ (Figure 7d). PSS yielded surface features co-directional with calcite's [010] axis (Figure 7e), whereas

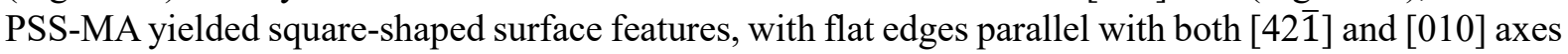
(Figure 7f).

Additive-Directed Changes in Morphology and Surface Patterns: Previous experiments have focused on the use of dissolution strategies to create calcite crystals with surface patterns. Calcite nanoshoot arrays were created via gentle dissolution in undersaturated solutions in the presence of a few selected additives - ammonium iodide and sulfate, ${ }^{24}$ ammonium chloride and acetate, ${ }^{9}$ and formamide ${ }^{10}$ - where this led to nanoshoots with high aspect ratios. Under these conditions dissolution leads to the formation of multiple etch pits over the crystal surface which subsequently increase in size and depth. They ultimately impinge on each other, generating an array of nanoshoots. The additives have minor effects on the morphologies of the nanoshoots, allowing them to be fine-tuned from curved to pyramidal. 
The work described here demonstrates that the formation of elaborate surface patterns is not restricted to dissolution processes, and that the use of additives that bind strongly to the surfaces of calcite crystals, and alternative synthesis conditions can give rise to a greater range of surface patterns. Effective patterning can also be achieved by exposing the crystals to a restructuring regime in which they undergo progressive dissolution and reprecipitation, where this effect is well-recognized and can lead to significant changes in the surfaces of $\mathrm{CaCO}_{3}$ crystals when they are incubated in the crystal growth solution for prolonged periods. ${ }^{3,23}$ By employing mixtures of selected additives, different crystallization conditions, and dissolution/restructuring regimes it is therefore possible to create a wide range of crystal morphologies and surface patterns.

The morphology changes and surface patterns formed can be rationalized based on interactions between the additives and the calcite surface. Most commonly this is binding to the step edges, where preferential binding to the acute or obtuse steps occurs depending on the structure of the additive and the crystallization conditions. Preferential binding is favored under slow growth conditions, but can be lost under conditions of rapid growth. ${ }^{25}$ Elongation of crystals along the $c$-axis is indicative of binding to the acute steps, ${ }^{2,3,26}$ whereas flattening along the $c$-axis is characteristic of preferential binding to the obtuse steps. ${ }^{27}$

The elongation of the crystals along the $c$-axis that occur with cp20k are therefore indicative of preferential binding to the acute steps (Figure 8a). This was confirmed using atomic force microscopy (AFM), where experiments were performed in a liquid cell. Rhombohedral calcite crystals were precipitated on the glass cover slip that seals the cell, and AFM was performed in Tapping Mode under slow flow of an additive-free calcium carbonate solution, and a solution containing [cp20k] $=0.005$ $\mathrm{mg} / \mathrm{mL}$ (Figure $8 \mathrm{~b}$ ). Under the conditions selected, calcite grows via a step growth mechanism and steps originate from screw dislocations present on the $\{104\}$ faces (Figure 8a). cp20k preferentially binds to the acute steps, resulting in significant step roughening and a reduction in the propagation rate. This is in agreement with previous data. ${ }^{12,13}$

That cp20k preferentially binds to the acute steps can be attributed to the large number of aspartic acid (Asp) and glutamic acid (Glu) residues present, where these are a hallmark of biomineralization proteins. ${ }^{28-30}$ These amino acids are known to bind to the acute steps on calcite, ${ }^{31}$ where this has been rationalized using computer simulations. ${ }^{2,} 26$ The data shown here demonstrate that this binding preference is maintained even when these groups are present on a protein that is much larger $(\approx 3 \mathrm{~nm})$ than the $0.31 \mathrm{~nm}$ height of the calcite steps. ${ }^{32}$ This suggests that there is sufficient conformational freedom for the amino acid side chains to adopt ideal positions on the steps. Indeed, many biomineralization proteins lack a defined tertiary structure, ${ }^{33,34}$ and exhibit an acute step preference. It is also noted that metal ions (e.g. $\left.\mathrm{Mg}^{2+}\right)^{1,17}$, small molecules (e.g. Asp and citric acid), ${ }^{1,26}$ proteins (e.g, asprich), ${ }^{29}$ vesicles (e.g. featuring poly(methacrylic acid), ${ }^{35}$ and latex beads ${ }^{36}$ all demonstrate preference for acute steps due to their chemistry, even if they are 10-1000x larger than the step height itself.

Although many additives preferentially bind to acute steps, they do not all exhibit the same incorporation behavior. In our system cp20k is confined exclusively to the outer layers of calcite. GFP ${ }^{37}$ and labelled proteins isolated from Pinctada fucata shells ${ }^{38,39}$ behave similarly, whereas GFP-purlucin conjugates, ${ }^{37}$ fluorescent dyes, ${ }^{25}$ carbon nanodots, ${ }^{40}$ and polymer-coated nanoparticles ${ }^{41}$ incorporate throughout the crystalline interior. For larger structures, such as vesicles and nanoparticles, incorporation is controlled by the length of stabilizing polymers, where longer chains allow incorporation throughout the interior. ${ }^{36,42}$

The ability of additives to modify morphologies or to become incorporated is ultimately determined by their residence times on the crystal surface as compared with growth rate of the crystal. Therefore, a spectrum of different effects can be observed ranging from strong morphological effects and poor occlusion to weak morphological effects and efficient occlusion. These are necessarily determined both by the additive itself and the crystallization conditions used, ${ }^{3,25}$ as observed here in the different surface morphologies observed with the ADM and CDM methods.

The striations seen on the surfaces of calcite grown in the presence of cp20k also reflect its interaction with the acute steps. As is shown in Figure 4, growth of calcite in the presence of cp20k results in

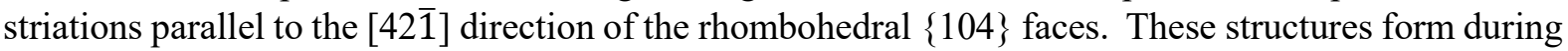
dissolution/reprecipitation processes and reflect the higher growth rate at the obtuse as compared with 
the acute steps (Figure 8c). This results in an elongation of surface features along the $c$-axis, in common with the changes that occur in the macroscopic morphology. Notably, surface structures with the same direction of elongation arise with other additives that preferentially bind to the acute steps including PAA, $\mathrm{Mg}^{2+}$ ions and formamide (Figure 7). Strong binding of acute-preferring additive to acute steps also prevents nucleation of new structures during restructuring.

These striations therefore appear predominantly around the obtuse vertex where the additive interaction is weakest. Additives that preferentially bind to the obtuse steps are less common. However, PSS is recognized to bind in this way, ${ }^{43}$ where macroscopic crystals display a compression along the $c$-axis and the formation of new $\{001\}$ pseudo faces (Figure 8a). ${ }^{44}$ Again, the surface striations observed on the crystal faces reflect this mode of interaction, and run parallel to the [010] direction (Figure 8c). Our data also demonstrate that more complex surface structures can be generated by employing more than one additive and/or by controlling dissolution or restructuring processes.

\section{Conclusions}

Soluble additives are widely used to control crystal morphologies, sizes and polymorph. Here, we demonstrate that they can also be used to generate distinct surface patterns on calcite crystals. Notably, this can be achieved by simply incubating the crystals in the crystal growth solution containing the additives, when the surface undergoes a continuous dissolution/reprecipitation process such that the surface features are constrained to the surface of the crystal. This mechanism is therefore quite distinct to the dissolution-based process used to generate arrays of nanoshoots on calcite surfaces, and the structure of the surface features can be modulated by using mixtures of additives. Finally, our study highlights the potential of using surface patterning as an indicator of the crystal/ additive interactions, where limited changes in crystal morphologies may occur at low additive concentrations.

\section{Experimental Section}

Crystal Growth Studies. Carbonate Direct Method (CDM). Calcium concentration ( $\left.\left[\mathrm{Ca}^{2+}\right]\right)$ was fixed at $5 \mathrm{mM}$ in all experiments. The concentration of cp20k ([cp20k]) was varied across a range of values $([\mathrm{cp} 20 \mathrm{k}]=0,0.001,0.005,0.015,0.025,0.05,0.075$ and $0.095 \mathrm{mg} / \mathrm{mL})$. In samples prepared by carbonate direct mixing $(\mathrm{CDM})$, reactions were initiated by the addition of $\mathrm{Na}_{2} \mathrm{CO}_{3}$ such that the initial concentration of carbonate was equimolar to that of calcium (i.e. $\left[\mathrm{Ca}^{2+}\right]=\left[\mathrm{CO}_{3}{ }^{2+}\right]=5 \mathrm{mM}$ ) and allowed to react for 5 days at room temperature. All experiments were conducted in $2 \mathrm{~mL}$ volumes, where appropriate volumes of stock were diluted with DI water within the well. Each well was charged with a clean glass substrate.

Ammonia Diffusion Method (ADM). $\left[\mathrm{Ca}^{2+}\right]$ was fixed at $5 \mathrm{mM}$ in all experiments. The concentration of cp20k ([cp20k]) was fixed at $[\mathrm{cp} 20 \mathrm{k}]=0.015 \mathrm{mg} / \mathrm{mL}$. In samples prepared by ammonia diffusion method (ADM), plastic well plates charged with a $\mathrm{CaCl}_{2} / \mathrm{cp} 20 \mathrm{k}$ aqueous solution and were covered with Parafilm, and a hole was punched in the top of each well before introduction to a $\mathrm{NH}_{3} / \mathrm{CO}_{2}$ rich atmosphere in a $15 \mathrm{~L}$ incubator containing $\approx 5 \mathrm{~g}\left(\mathrm{NH}_{4}\right)_{2} \mathrm{CO}_{3}$ and $20 \mathrm{~mL}$ DI water in separate Petri dishes. Growth was allowed to occur over 5 days at room temperature.

Dissolution and restructuring studies. Dissolution or restructuring on unmodified calcite seeds occurred in aqueous additive solutions at $65^{\circ} \mathrm{C}$ for $16 \mathrm{~h}$. The well plate was either covered with a well-plate cover and sealed with Parafilm (dissolution) or left open to allow evaporation of water (restructuring).

Mixed additive studies. $\left[\mathrm{Ca}^{2+}\right]\left(=\left[\mathrm{CO}_{3}{ }^{2-}\right]\right.$ for $\left.\mathrm{CDM}\right)$ was fixed at $5 \mathrm{mM}$. [cp20k] was fixed at 0.015 $\mathrm{mg} / \mathrm{mL}$. Magnesium to calcium ratio $\left(\left[\mathrm{Mg}^{2+}\right] /\left[\mathrm{Ca}^{2+}\right]\right)$ was set at $0,0.5$ or 1 , which implies the precipitation of calcite in the presence of $0,2.5$ and $5 \mathrm{mM}$ magnesium ions respectively. Well plates for either ADM or CDM studies were prepared as described above.

The influence of alternative additives. All conditions for growth, dissolution and restructuring were identical to the protocols described above, except cp20k was replaced with other additives PAA, PSS, PSS-MA, $\mathrm{Mg}^{2+}$ and formamide. The final concentrations for each additive in each experiment are given in Table S2. These values represent the experiments described in the current study, while other concentrations were also examined during screening experiments.

Time-dependent morphology evolution studies. In order to examine the evolution of the influence on morphology by cp20k, 4 separate but identical CDM reactions were initiated and conducted 
simultaneously, but terminated at different times $(10,30,60$ and $120 \mathrm{~min})$. Each well was charged with a clean glass slide, $50 \mu \mathrm{L}$ filtered $200 \mathrm{mM} \mathrm{CaCl}_{2} .2 \mathrm{H}_{2} \mathrm{O}$ aqueous solution and $300 \mu \mathrm{L} 0.1 \mathrm{mg} / \mathrm{mL}$ filtered cp20k aqueous solution, followed by $1.6 \mathrm{~mL}$ filtered DI water, resulting in $1.95 \mathrm{~mL}$ of total volume within the well. $50 \mu \mathrm{L}$ filtered $200 \mathrm{mM} \mathrm{Na}{ }_{2} \mathrm{CO}_{3}$ aqueous solution was added followed by stirring to initiate the crystallization. At the assigned time interval, reactions were quenched by removing the glass slide and rinsing with DI water and ethanol.

Characterization. Optical microscopy (OM) and polarized light microscopy (PLM). OM and PLM were conducted on calcite samples grown on glass substrates with Nikon Eclipse LV100 microscope controlled with NIS-Elements BR software. Micrographs were captured digitally used Nikon DSFi1/Nikon Digital Sight CCD camera.

Raman microscopy. Raman microscopy was conducted on calcite samples grown on glass substrates using a Renishaw inVia Raman Microscope (785 nm laser) with a 50x objective using MS20 encoded sample stage control through rollerball XYZ peripheral. Data acquisition was undertaken with Renishaw WiRE 3.4 with a laser intensity of $0.1 \%$ under 3 accumulated acquisitions $(3 \mathrm{x}$ scan time 30 s) between 1200 to $100 \mathrm{~cm}^{-1}$.

Scanning electron microscopy (SEM). SEM was conducted on FEI NanoSEM Nova 450 from samples grown directly on clean glass substrates. Samples were mounted on aluminum stubs with double sided $\mathrm{Cu}$ tape, with tape folded to a portion of the top surface of the substrate to minimize charging. All samples were coated with $2 \mathrm{~nm}$ Ir conductive layer prior to analysis.

For SEM analysis of samples subjected to mechanical fracturing, glass substrates loaded with samples were covered gently with a fresh glass slide, such that the calcite crystals were between the glass layers. A small amount of pressure was applied by hand, followed by a $30-40^{\circ}$ rotation, which caused fracturing and spreading of the fractured components. This was then prepared and imaged as described above.

Transmission electron microscopy (TEM). TEM was conducted on FEI Tecnai TF20 FEG-TEM fitted with an Oxford Instruments INCA 350 EDX system/80 mm X-Max SDD detector and a Gatan Orius SC600A CCD camera operating at $200 \mathrm{kV}$. Samples were loaded onto carbon coated $\mathrm{Cu}$ grids.

Focused ion beam (FIB) lithography. FIB lithography was conducted on FEI Dual Beam system equipped with a $30 \mathrm{kV}$ Ga beam and a field emission electron gun (FEG) operated at $5 \mathrm{kV}$.

Confocal laser fluorescence microscopy (CLFM). CLFM was conducted on Zeiss LSM510 Upright Confocal Microscope using samples grown directly on clean glass substrates under oil immersion where required. Laser and imaging settings were controlled with Zeiss ZEN software, where preset conditions for FITC were used (excitation at $488 \mathrm{~nm}$, low pass emission filter at $505 \mathrm{~nm}$ ).

Liquid cell Atomic Force Microscope (AFM). AFM images were recorded using a Bruker Multimode 8 with a NanoScope V controller. Images were collected using silicon nitride cantilevers with nominal spring constants of $0.35 \mathrm{~N} / \mathrm{m}$ (Bruker SNL-10). Rhombohedral calcite seed crystals $80 \mu \mathrm{m}$ in size were pre-precipitated onto glass cover slips under additive-free conditions by mixing equal volumes of 10 $\mathrm{mM} \mathrm{CaCl}$ and $\mathrm{NaHCO}_{3}$ aqueous solutions. In situ measurements were collected whilst flowing supersaturated calcium carbonate growth solutions over the seed crystals at $0.1-0.25 \mathrm{~mL} / \mathrm{min}$. The influence of the additives on the calcite growth was investigated by growing the calcite seeds in the presence and absence of additives, using a fixed calcium concentration and ionic strength, as used previously. ${ }^{15}$ The growth solutions provided stable, slow growth conditions which can be effectively studied on an AFM time-scale. The concentration of cp20k was kept at $0.005 \mathrm{mg} / \mathrm{mL}$. In situ imaging was performed in contact mode or Tapping Mode $^{\mathrm{TM}}$ where appropriate.

\section{SUPPORTING INFORMATION}

The Supporting Information is available free of charge of the ACS Publications website at DOI: XXX. Experimental details of the cp20k expression, materials, stock solution preparation, example crystal growth protocols, cp20k fluorescent tagging, image analysis and modelling techniques; Tables S1 and S2; and Figures S1-S9.

\section{AUTHOR INFORMATION}

\section{Corresponding Author}


*Email: davegreen5466@gmail.com

\section{Present Addresses}

$\S$ School of Physical Sciences and Computing, University of Central Lancashire, Preston, PR1 2HE, UK

\section{Notes}

The authors declare no competing financial interest. Data that support the findings of this study are available in the Research Data Leeds Repository with the identifier http://doi.org/10.5518/615. ${ }^{45}$

\section{ACKNOWLEDGMENTS}

This work was supported by an Engineering and Physical Sciences Research Council (EPSRC) grant EP/P005233/1. Y.S. and W.O. would like to thank Professor Kei Kamino for his helpful advice concerning cp20k expression and purification. D.C.G would like to thank the Bio-imaging Facility in the Faculty of Biological Sciences, University of Leeds for access to and assistance with confocal laser microscopy. Finally, D.C.G. dedicates this work, with great pride and pleasure, to Arvid Sten Green and Kristoffer Storm Green, who arrived 18 January 2019.

\section{REFERENCES}

(1) Meldrum, F. C.; Hyde, S. T., Morphological influence of magnesium and organic additives on the precipitation of calcite. $J$ Cryst Growth 2001, 231, 544-558.

(2) Orme, C. A.; Noy, A.; Wierzbicki, A.; McBride, M. T.; Grantham, M.; Teng, H. H.; Dove, P. M.; DeYoreo, J. J., Formation of chiral morphologies through selective binding of amino acids to calcite surface steps. Nature 2001, 411, 775-779.

(3) Kim, Y. Y.; Schenk, A. S.; Ihli, J.; Kulak, A. N.; Hetherington, N. B. J.; Tang, C. C.; Schmahl, W. W.; Griesshaber, E.; Hyett, G.; Meldrum, F. C., A critical analysis of calcium carbonate mesocrystals. Nat Commun 2014, 5., 4341

(4) Kristensen, A.; Yang, J. K. W.; Bozhevolnyi, S. I.; Link, S.; Nordlander, P.; Halas, N. J.; Mortensen, N. A., Plasmonic colour generation. Nat Rev Mater 2017, 2, 16088

(5) Brongersma, M. L.; Cui, Y.; Fan, S. H., Light management for photovoltaics using high-index nanostructures. Nat Mater 2014, 13, 451-460.

(6) Nishino, Y.; Oaki, Y.; Imai, H., Magnesium-Mediated Nanocrystalline Mosaics of Calcite. Cryst Growth Des 2009, 9, 223-226.

(7) Imai, H.; Terada, T.; Yamabi, S., Self-organized formation of a hierarchical self-similar structure with calcium carbonate. Chem Commun 2003, 4, 484-485.

(8) Oaki, Y.; Hayashi, S.; Imai, H., A hierarchical self-similar structure of oriented calcite with association of an agar gel matrix: inheritance of crystal habit from nanoscale. Chem Commun 2007, 27, 2841-2843.

(9) Long, X.; Meng, R. J.; Wu, W. K.; Ma, Y. R.; Yang, D.; Qi, L. M., Calcite Microneedle Arrays Produced by Inorganic Ion-Assisted Anisotropic Dissolution of Bulk Calcite Crystal. Chem-Eur J 2014, 20, 4264-4272.

(10) Yu, H. D.; Yang, D. P.; Wang, D. S.; Han, M. Y., Top-Down Fabrication of Calcite Nanoshoot Arrays by Crystal Dissolution. Adv Mater 2010, 22, 3181-3184

(11) He, L. S.; Zhang, G.; Qian, P. Y., Characterization of Two 20kDa-Cement Protein (cp20k) Homologues in Amphibalanus amphitrite. Plos One 2013, 8, e64130

(12) Mori, Y.; Urushida, Y.; Nakano, M.; Uchiyama, S.; Kamino, K., Calcite-specific coupling protein in barnacle underwater cement. FEBS 2007, 274, 6436-6446.

(13) So, C. R.; Liu, J.; Fears, K. P.; Leary, D. H.; Golden, J. P.; Wahl, K. J., Self-Assembly of Protein Nanofibrils Orchestrates Calcite Step Movement through Selective Nonchiral Interactions. ACS Nano 2015, 9, 5782-5791.

(14) Ihli, J.; Bots, P.; Kulak, A.; Benning, L. G.; Meldrum, F. C., Elucidating Mechanisms of Diffusion-Based Calcium Carbonate Synthesis Leads to Controlled Mesocrystal Formation. Adv Funct Mater 2013, 23, (15), 1965-1973. 
(15) Marzec, B.; Green, D. C.; Holden, M. A.; Cote, A. S.; Ihli, J.; Khalid, S.; Kulak, A.; Walker, D.; Tang, C.; Duffy, D. M.; Kim, Y. Y.; Meldrum, F. C., Amino Acid Assisted Incorporation of Dye Molecules within Calcite Crystals. Angew Chem Int Edit 2018, 57, 8623-8628.

(16) Astilleros, J. M.; Fernandez-Diaz, L.; Putnis, A., The role of magnesium in the growth of calcite: An AFM study. Chem Geol 2010, 271, 52-58.

(17) Davis, K. J.; Dove, P. M.; De Yoreo, J. J., The role of $\mathrm{Mg}^{2+}$ as an impurity in calcite growth. Science 2000, 290, 1134-1137.

(18) Fernandez-Diaz, L.; Astilleros, J. M.; Pina, C. M., The morphology of calcite crystals grown in a porous medium doped with divalent cations. Chem Geol 2006, 225, 314-321.

(19) Wada, N.; Horiuchi, N.; Nakamura, M.; Hiyama, T.; Nagai, A.; Yamashita, K., Effect of Poly(acrylic acid) and Polarization on the Controlled Crystallization of Calcium Carbonate on SinglePhase Calcite Substrates. Cryst Growth Des 2013, 13, 2928-2937.

(20) Kim, Y. Y.; Freeman, C. L.; Gong, X. Q.; Levenstein, M. A.; Wang, Y. W.; Kulak, A.; AnduixCanto, C.; Lee, P. A.; Li, S. B.; Chen, L.; Christenson, H. K.; Meldrum, F. C., The Effect of Additives on the Early Stages of Growth of Calcite Single Crystals. Angew Chem Int Edit 2017, 56, 11885-11890.

(21) Wang, T. P.; Antonietti, M.; Colfen, H., Calcite mesocrystals: "Morphing" crystals by a polyelectrolyte. Chem-Eur J 2006, 12, 5722-5730.

(22) Song, R. Q.; Colfen, H.; Xu, A. W.; Hartmann, J.; Antonietti, M., Polyelectrolyte-Directed Nanoparticle Aggregation: Systematic Morphogenesis of Calcium Carbonate by Nonclassical Crystallization. ACS Nano 2009, 3, 1966-1978.

(23) Song, R. Q.; Xu, A. W.; Antonietti, M.; Colfen, H., Calcite Crystals with Platonic Shapes and Minimal Surfaces. Angew Chem Int Edit 2009, 48, 395-399.

(24) Meng, R. J.; Ma, Y. R.; Long, X.; Yang, D.; Qi, L. M., Calcite microrod arrays fabricated via anisotropic dissolution of calcite in the presence of $\mathrm{NH}_{4} \mathrm{I}$ and $\left(\mathrm{NH}_{4}\right)_{2} \mathrm{SO}_{4}$. Crystengcomm 2013, 15, $8867-8873$.

(25) Green, D. C.; Ihli, J.; Thornton, P. D.; Holden, M. A.; Marzec, B.; Kim, Y. Y.; Kulak, A. N.; Levenstein, M. A.; Tang, C.; Lynch, C.; Webb, S. E. D.; Tynan, C. J.; Meldrum, F. C., 3D visualization of additive occlusion and tunable full-spectrum fluorescence in calcite. Nat Commun 2016, 7, 13524

(26) Kim, Y. Y.; Carloni, J. D.; Demarchi, B.; Sparks, D.; Reid, D. G.; Kunitake, M. E.; Tang, C. C.; Duer, M. J.; Freeman, C. L.; Pokroy, B.; Penkman, K.; Harding, J. H.; Estro, L. A.; Baker, S. P.; Meldrum, F. C., Tuning hardness in calcite by incorporation of amino acids. Nat Mater 2016, 15, 903910.

(27) Rajam, S.; Mann, S., Selective Stabilization of the (001) Face of Calcite in the Presence of Lithium. J Chem Soc Chem Commun 1990, 1789-1791.

(28) Fu, G.; Qiu, S. R.; Orme, C. A.; Morse, D. E.; De Yoreo, J. J., Acceleration of calcite kinetics by abalone nacre proteins. Adv Mater 2005, 17, 2678-2683

(29) Politi, Y.; Mahamid, J.; Goldberg, H.; Weiner, S.; Addadi, L., Asprich mollusk shell protein: in vitro experiments aimed at elucidating function in $\mathrm{CaCO}_{3}$ crystallization. Crystengcomm 2007, 9, 11711177.

(30) Hong, M. N.; Moreland, K. T.; Chen, J. J.; Teng, H. H.; Thalmann, R.; De Yoreo, J. J., Effect of Otoconial Proteins Fetuin A, Osteopontin, and Otoconin 90 on the Nucleation and Growth of Calcite. Cryst Growth Des 2015, 15, 129-136.

(31) Green, D. C.; Ihli, J.; Kim, Y. Y.; Chong, S. Y.; Lee, P. A.; Empson, C. J.; Meldrum, F. C., Rapid Screening of Calcium Carbonate Precipitation in the Presence of Amino Acids: Kinetics, Structure, and Composition. Cryst Growth Des 2016, 16, 5174-5183.

(32) Elhadj, S.; Rioux, R. M.; Dickey, M. D.; DeYoreo, J. J.; Whitesides, G. M., Subnanometer Replica Molding of Molecular Steps on Ionic Crystals. Nano Lett 2010, 10, 4140-4145.

(33) Wustman, B. A.; Weaver, J. C.; Morse, D. E.; Evans, J. S., Characterization of a Ca(II)-, mineral-interactive polyelectrolyte sequence from the adhesive elastomeric biomineralization protein lustrin A. Langmuir 2003, 19, 9373-9381.

(34) Xu, G. Z.; Evans, J. S., Model peptide studies of sequence repeats derived from the intracrystalline biomineralization protein, SM50. I. GVGGR and GMGGQ repeats. Biopolymers 1999, 49, 303-312.

(35) Kim, Y. Y.; Semsarilar, M.; Carloni, J. D.; Cho, K. R.; Kulak, A. N.; Polishchuk, I.; Hendley, C. T.; Smeets, P. J. M.; Fielding, L. A.; Pokroy, B.; Tang, C. C.; Estroff, L. A.; Baker, S. P.; Armes, S. 
P.; Meldrum, F. C., Structure and Properties of Nanocomposites Formed by the Occlusion of Block Copolymer Worms and Vesicles Within Calcite Crystals. Adv Funct Mater 2016, 26, 1382-1392.

(36) Kim, Y. Y.; Ribeiro, L.; Maillot, F.; Ward, O.; Eichhorn, S. J.; Meldrum, F. C., Bio-Inspired Synthesis and Mechanical Properties of Calcite-Polymer Particle Composites. Adv Mater 2010, 22, 2082-2086

(37) Weber, E.; Bloch, L.; Guth, C.; Fitch, A. N.; Weiss, I. M.; Pokroy, B., Incorporation of a Recombinant Biomineralization Fusion Protein into the Crystalline Lattice of Calcite. Chem Mater 2014, 26, 4925-4932.

(38) Liu, C.; Du, J. Z.; Xie, L. P.; Zhang, R. Q., Direct Observation of Nacre Proteins in the Whole Calcite by Super resolution Microscopy Reveals Diverse Occlusion Patterns. Cryst Growth Des 2017, 17, 1966-1976.

(39) Liu, C.; Xie, L. P.; Zhang, R. Q., Heterogeneous distribution of dye-labelled biomineralizaiton proteins in calcite crystals. Scientific Reports 2015, 5, 18338

(40) Green, D. C.; Holden, M. A.; Levenstein, M. A.; Zhang, S. H.; Johnson, B. R. G.; de Pablo, J. G.; Ward, A.; Botchway, S. W.; Meldrum, F. C., Controlling the fluorescence and room-temperature phosphorescence behaviour of carbon nanodots with inorganic crystalline nanocomposites. Nat Commun 2019, 10, 206

(41) Magnabosco, G.; Polishchuk, I.; Palomba, F.; Rampazzo, E.; Prodi, L.; Aizenberg, J.; Pokroy, B.; Falini, G., Effect of Surface Chemistry on Incorporation of Nanoparticles within Calcite Single Crystals. Cryst Growth Des 2019, 19, 4429-4435.

(42) Ning, Y.; Han, L. J.; Douverne, M.; Penfold, N. J. W.; Derry, M. J.; Meldrum, F. C.; Armes, S. P., What Dictates the Spatial Distribution of Nanoparticles within Calcite? J Am Chem Soc 2019, 141, 2481-2489.

(43) Smeets, P. J. M.; Cho, K. R.; Sommerdijk, N. A. J. M.; De Yoreo, J. J., A Mesocrystal-Like Morphology Formed by Classical Polymer-Mediated Crystal Growth. Adv Funct Mater 2017, 27, 1701658

(44) Schenk, A. S.; Zlotnikov, I.; Pokroy, B.; Gierlinger, N.; Masic, A.; Zaslansky, P.; Fitch, A. N.; Paris, O.; Metzger, T. H.; Colfen, H.; Fratzl, P.; Aichmayer, B., Hierarchical Calcite Crystals with Occlusions of a Simple Polyelectrolyte Mimic Complex Biomineral Structures. Adv Funct Mater 2012, $22,4668-4676$.

(45) Green, D. C.; Dataset for Skin-deep Surface Patterning of Calcite. 2019 Research Data Leeds Repository, http://doi.org/10.5518/615 (accessed 10/07/2019) 


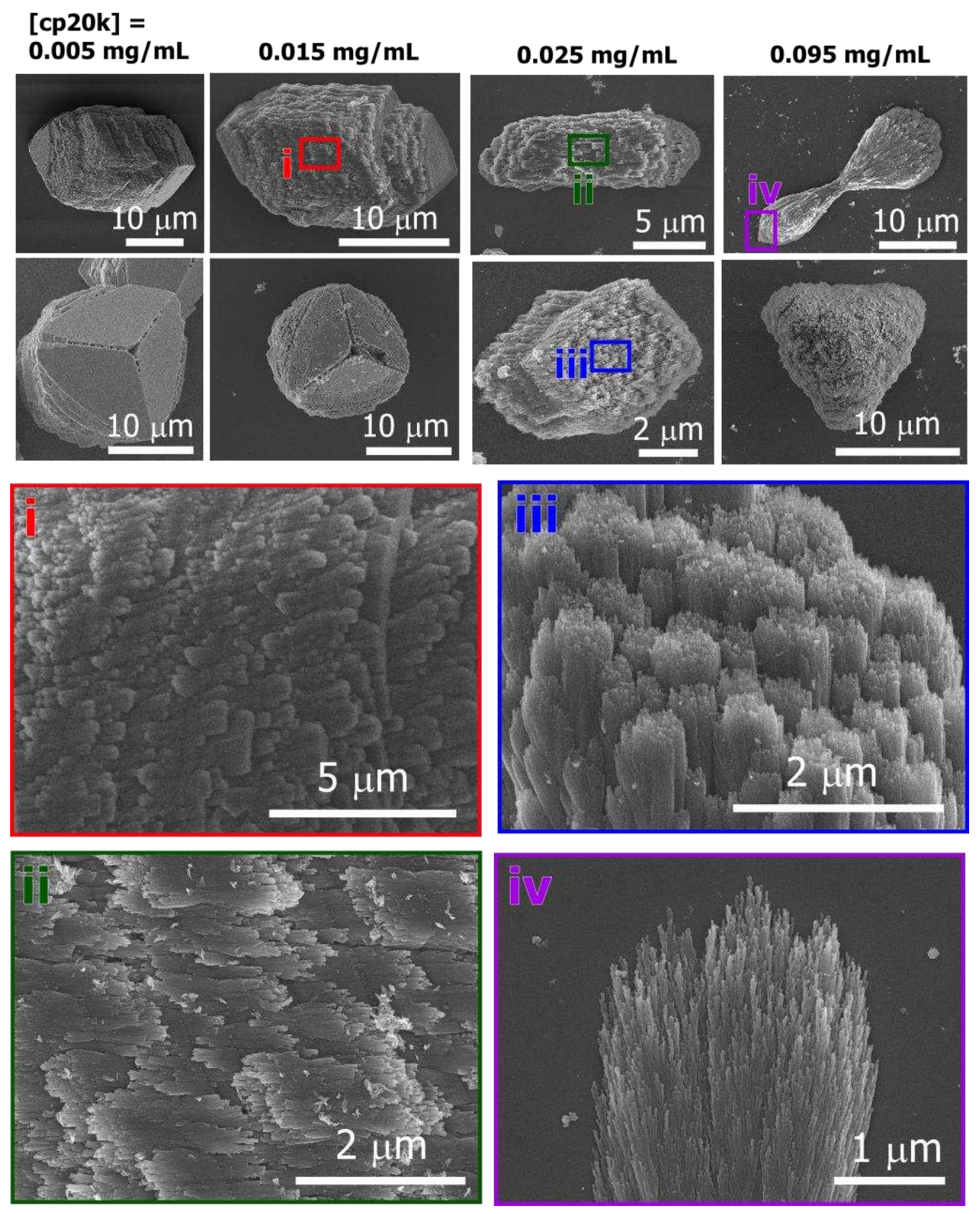

Figure 1: SEM micrographs of calcite grown in the presence of different concentrations of cp20k by $\mathrm{CDM}\left(\left[\mathrm{Ca}^{2+}\right]=\left[\mathrm{CO}_{3}{ }^{2-}\right]=5 \mathrm{mM}\right)$. Micrographs show crystals approximately orientated (104)-up (above) and (001)-up (below). Higher magnification SEM micrographs of regions denoted i - iv. 


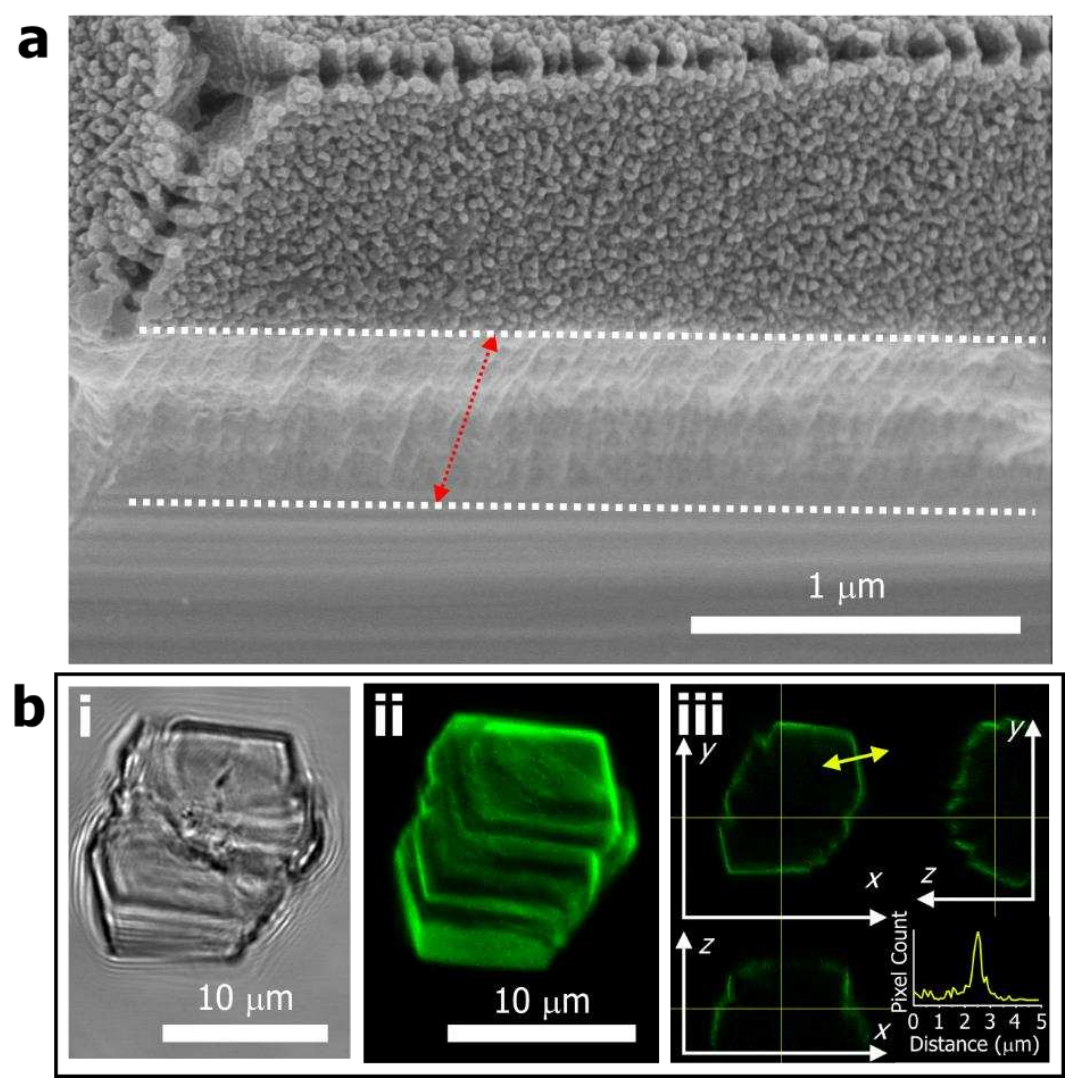

Figure 2: a) SEM micrograph of a fractured calcite single crystals showing the outermost region (upper and lower limits marked with dotted white lines) was much rougher than the core, and the measured depth (marked with a red arrow) was $\approx 0.5 \mu \mathrm{m}$. b) optical micrograph (i) and CLFM $z$-projected micrograph (ii) of the same sample, showing cp20k is incorporated with calcite single crystals during precipitation. Orthogonal view micrographs (iii) showed that cp20k only incorporated in the outermost sections. Pixel count line profile (insert) at the yellow arrow indicated that $\mathrm{cp} 20 \mathrm{k}$ was incorporated to a depth $\approx 0.7 \mu \mathrm{m}$. 


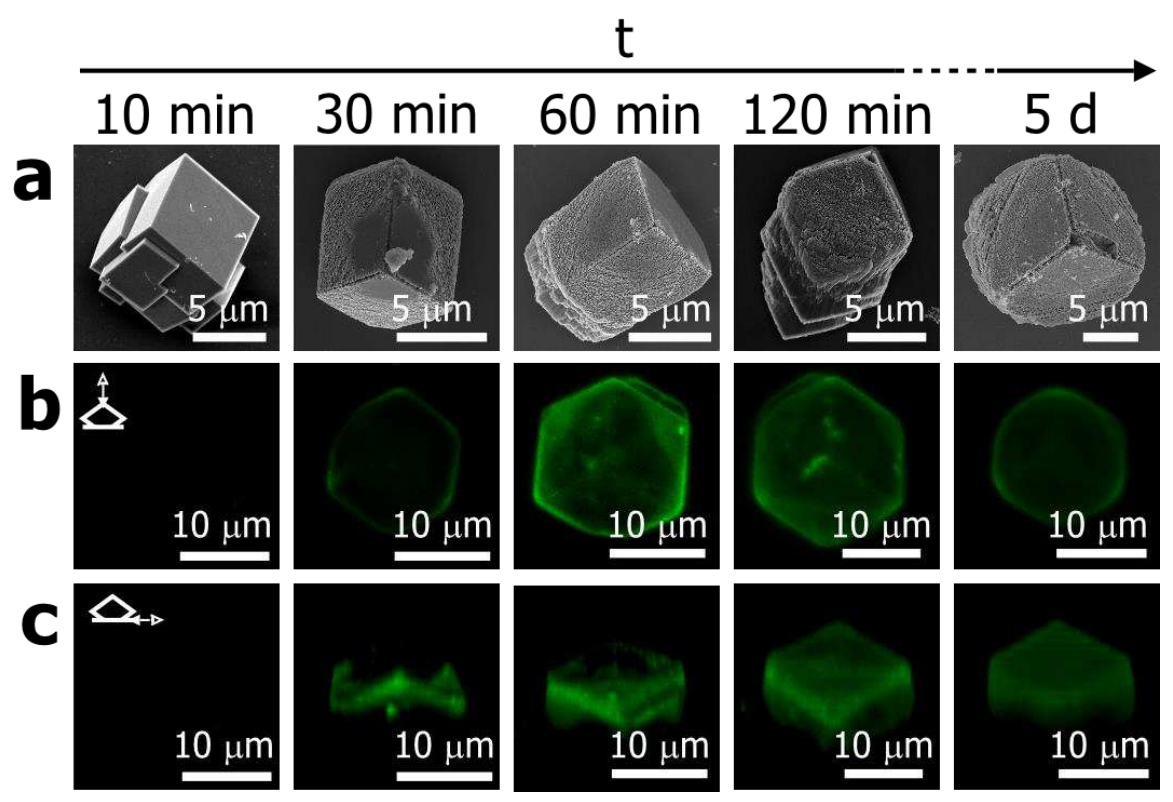

Figure 3: Representative SEM (a) CLFM (b and c) micrographs of calcite grown in the presence of cp20k $([\mathrm{cp} 20 \mathrm{k}]=0.015 \mathrm{mg} / \mathrm{mL}+$ FITC-conjugated cp20k $)$ by CDM $\left(\left[\mathrm{Ca}^{2+}\right]=\left[\mathrm{CO}_{3}{ }^{2-}\right]=5 \mathrm{mM}\right)$ taken at different times. $Z$-projected CLFM micrographs from $Z$-stacks (b) and side-on view of 3D rendered images (c) reveal increasing surface roughness with time. 


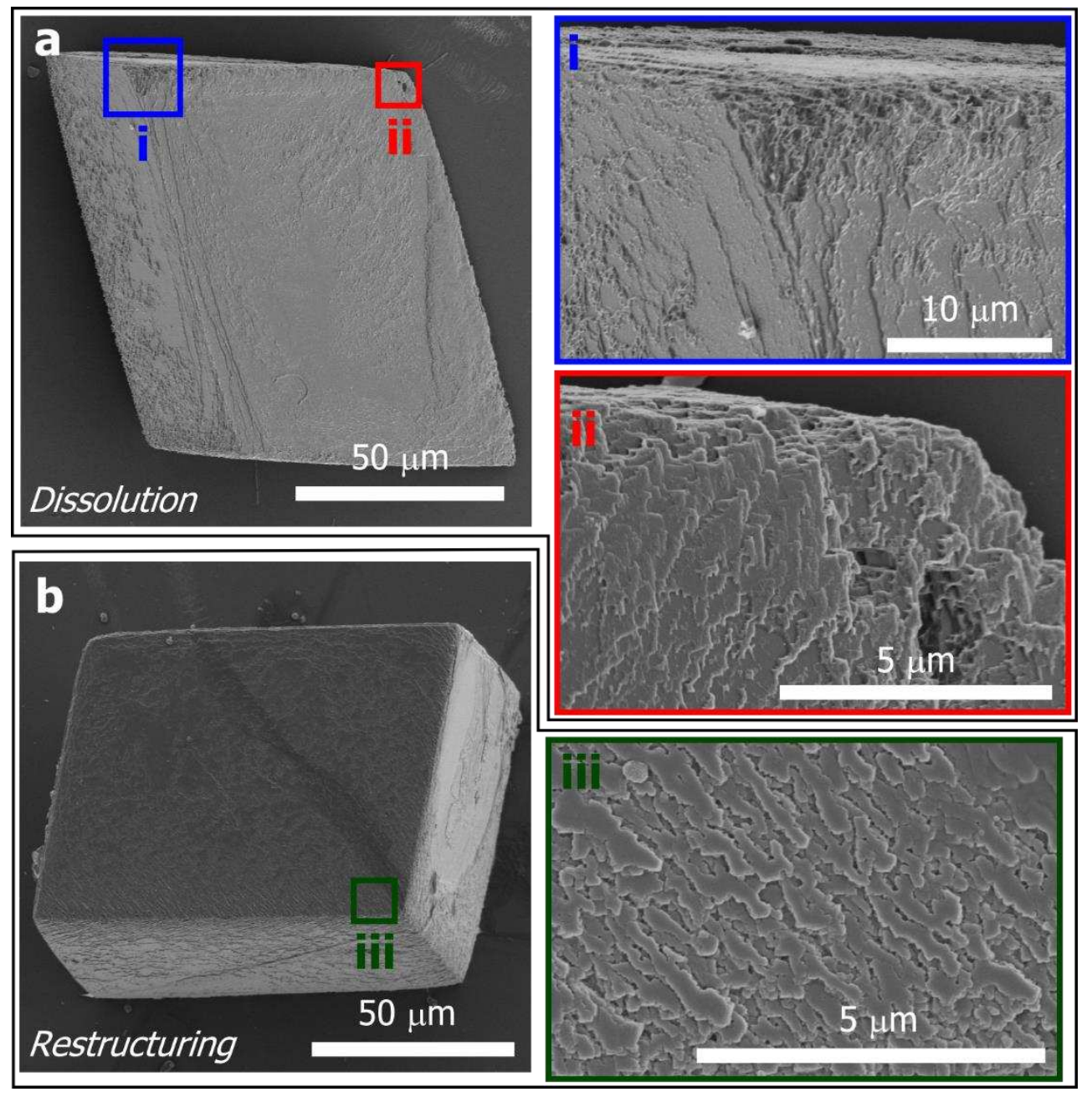

Figure 4: a) SEM micrographs of a calcite seed dissolved in the presence of $[\mathrm{cp} 20 \mathrm{k}]=0.015 \mathrm{mg} / \mathrm{mL}$. b) SEM micrograph of a calcite seed subjected to restructuring in the presence $[\mathrm{cp} 20 \mathrm{k}]=0.015 \mathrm{mg} / \mathrm{mL}$. 


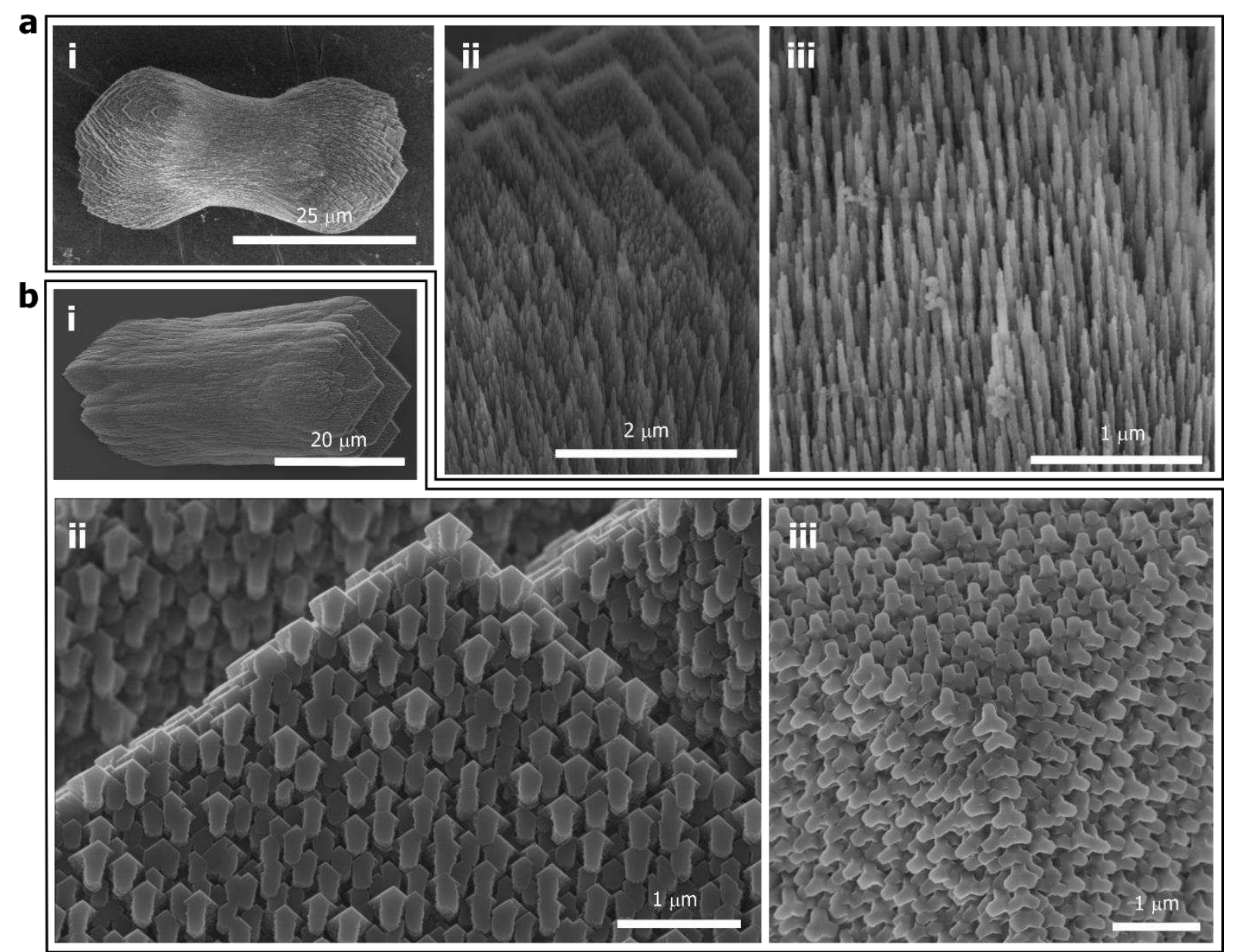

Figure 5: SEM micrographs of calcite grown under initial $\left[\mathrm{Mg}^{2+}\right] /\left[\mathrm{Ca}^{2+}\right]=0.5$, $[\mathrm{cp} 20 \mathrm{k}]=0.015 \mathrm{mg} / \mathrm{mL}$ and $\left[\mathrm{Ca}^{2+}\right]=5 \mathrm{mM}$, with CDM (a) and ADM (b). Low magnification micrographs details the overall morphology (i), while higher magnification micrographs reveal nanoshoot (ai and aii) and arrowshaped (bii and biii) surface decoration for CDM and ADM-prepared crystals respectively. 

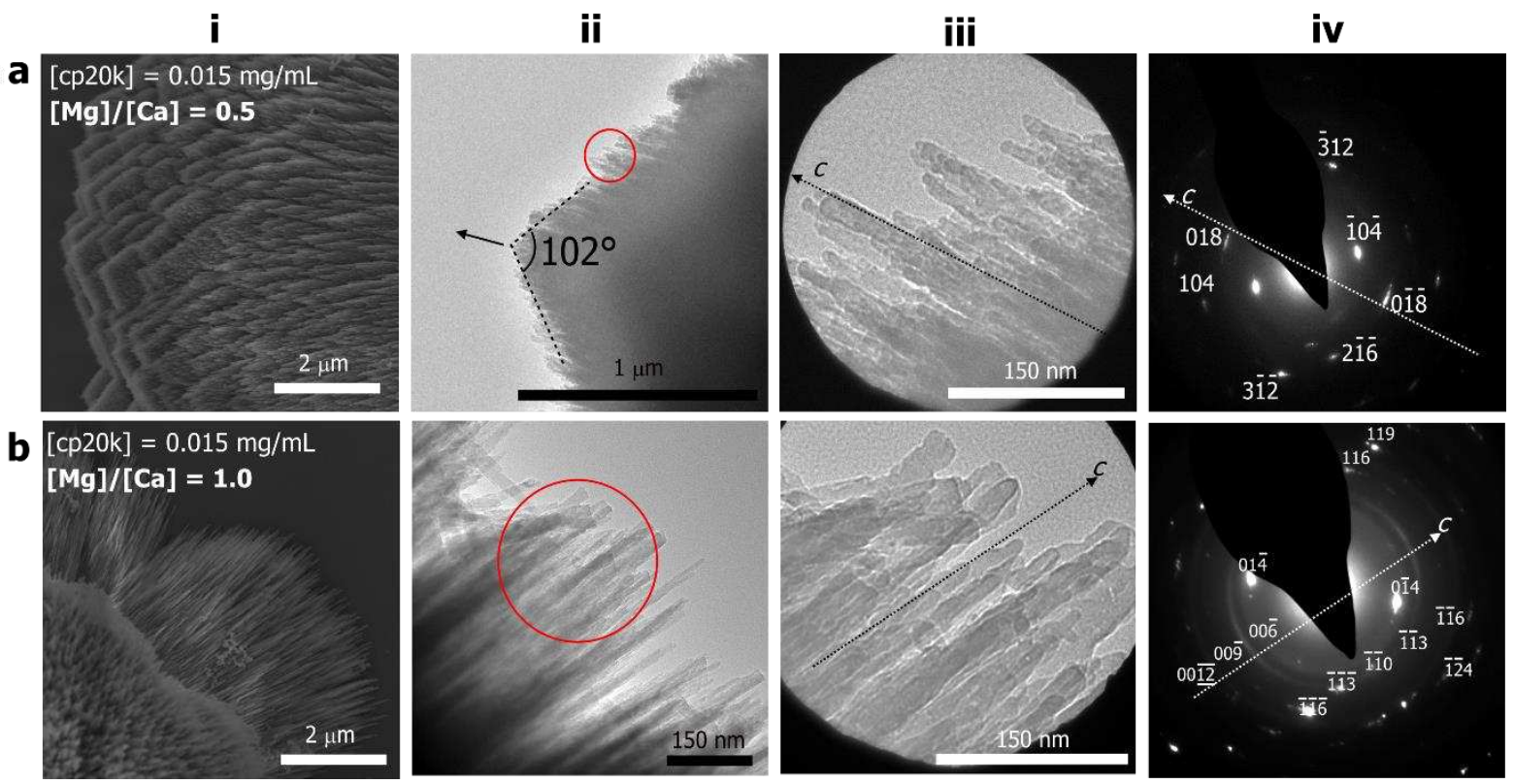

Figure 6: Characterization of calcite nanoshoots produced under CDM growth conditions with [cp20k] $=0.015 \mathrm{mg} / \mathrm{mL}$ and $\left[\mathrm{Mg}^{2+}\right] /\left[\mathrm{Ca}^{2+}\right]=0.5$ (a) or 1.0 (b). i) Representative SEM micrograph. ii) Low magnification TEM micrograph of the edge of a fractured crystal. iii) TEM micrograph of nanoshoots taken from area circled in red in ii. iv) SAED of area shown in iii. Both iii and iv are annotated with the crystallographic c axis as determined from SAED. 

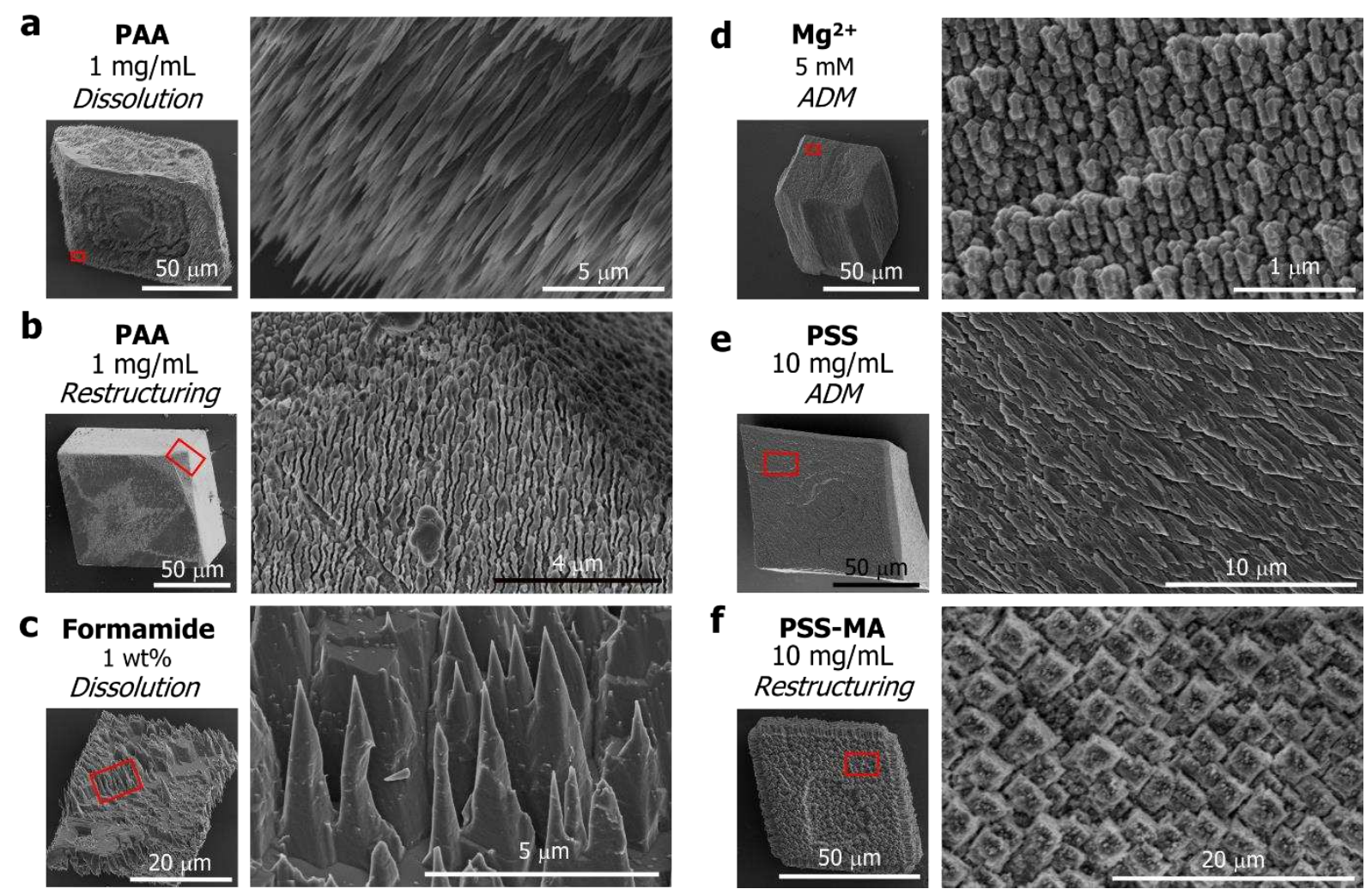

Figure 7: Low and high magnification SEM micrographs of additive-modified calcite surfaces prepared with various methods and additives as listed: a) PAA $(1 \mathrm{mg} / \mathrm{mL})$, dissolution; b) PAA $(1 \mathrm{mg} / \mathrm{mL})$, restructuring; c) Formamide (1 wt $\%$ ), dissolution; d) $\mathrm{Mg}^{2+}(5 \mathrm{mM}), \mathrm{ADM}$; e) PSS (10 mg/mL), ADM; f) PSS-MA $(10 \mathrm{mg} / \mathrm{mL})$, restructuring 


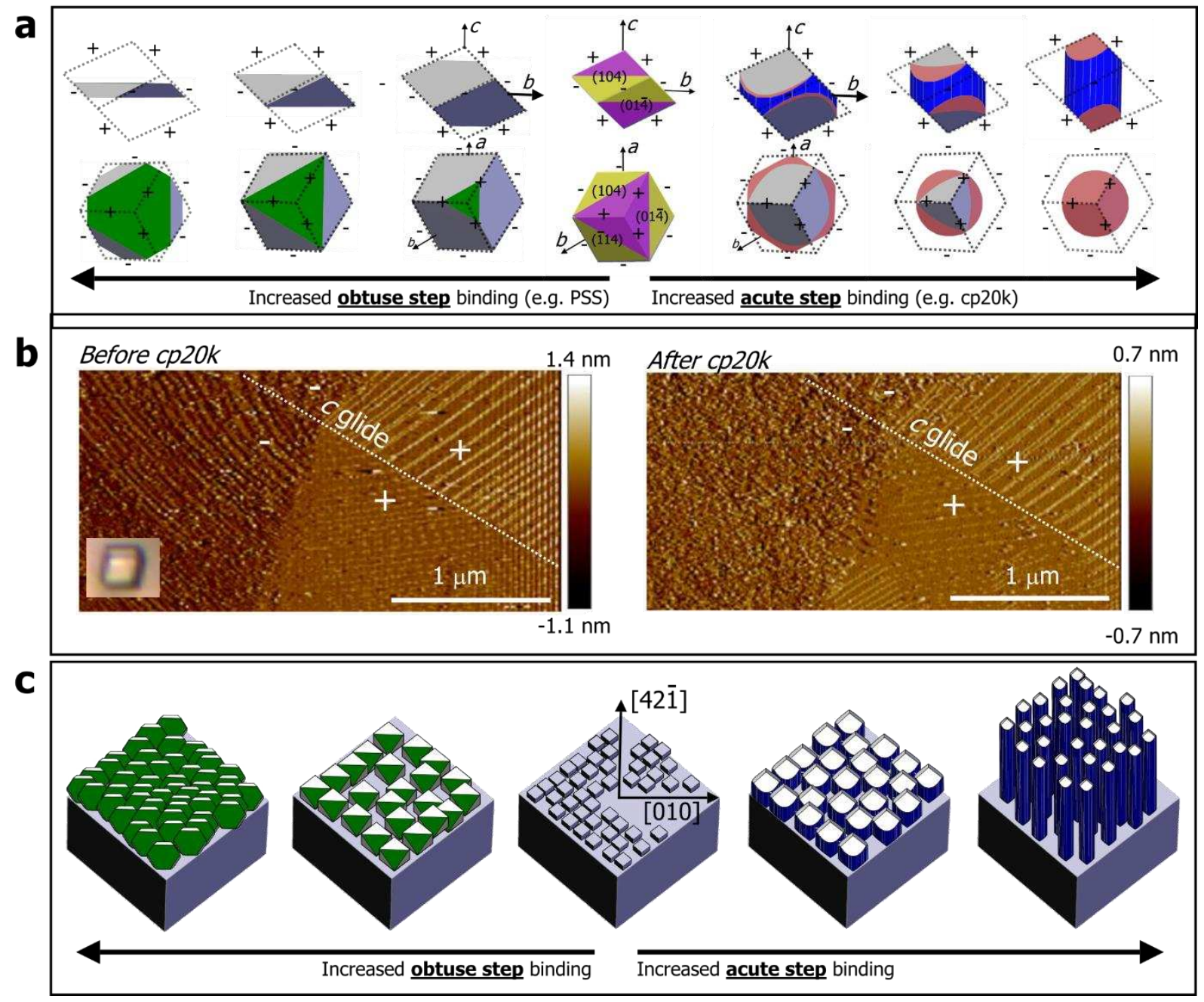

Figure 8: a) Schematic of equilibrium calcite rhombohedron (centre) as observed down a-axis (top) and c-axis (bottom). Acute and obtuse steps are labelled '-' and '+' respectively, with the acute and obtuse step-dominated growth sector shaded yellow and purple respectively. Increasing [cp20k] induces increasing surface roughness on $\{104\}$ faces (red) and elongation through increasing expression of pseudofaces (blue). Increasing obtuse-preferring additive concentration leads to crystal 'flattening' by increased expression of a pseudoface equivalent to (001) (green). b) Liquid-cell AFM micrographs, obtained from deflection data, revealing the shape of a calcite growth hillock before and after the addition of $[\mathrm{cp} 20 \mathrm{k}]=0.005 \mathrm{mg} / \mathrm{mL}$ (under growth conditions. Based on the crystal's orientation (optical micrograph insert) and the position of the c glide, only acute steps, marked with "-", are affected. c) Schematic showing idealized morphology of overgrowths on calcite during restructuring, which describe the origin of [010] or [42 $\overline{1}]$ striations after treatment with obtuse-or acute-preferential binding additives. Shading is the same as that in part a 